\title{
Assessment of Progressive Collapse in Reinforced Concrete Framed Structures Subjected to Seismic Actions
}

\author{
Sujaykumar R. Sanglikar, R. Prasanna Kumar and M.S. Bhandiwad
}

\begin{abstract}
Progressive collapse is a catastrophic structural event that occurs when failure of one or more structural member in the structure initiates a chain reaction resulting in partial or total collapse of the structure.To study the behavior of RC structure under the influence of seismic actions a load bearing vertical element like wall or column is removed and evaluated using nonlinear static pushdown analysis. For this a 3-D model is stimulated and a nonlinear static analysis is performed by removing a critical column at desired location in the plan prescribed by General Service Administration (GSA) guidelines. The importance of beams during a column loss is evaluated in the present study to resist possible progressive collapse.
\end{abstract}

Keywords--- Progressive Collapse, Nonlinear Analysis, Seismic Analysis, Demand Capacity Ratios, GSA

\section{INTRODUCTION}

$\mathrm{P}$ ROGRESSIVE collapse analysis has become a important aspect of design of structures due to increased terrorist activities involving bomb blasts vehicular impacts and aircraft collusionetc. In 1968 a gas explosion at $18^{\text {th }}$ story of 22 story height Ronan point apartment building brought down entire corner bay to the ground. This lead to investigations and studies to avoid progressive collapse. The most famous event ever was progressive collapse of 'World Trade Centre' building on September $11^{\text {th }} 2001$, the fire caused due to crash of boing 767 jetliner induced structural damage and weakened steel structure until trusses started to sag. This sagging lead the downward pull and increased downward load and Impact of the collapsing upper part of the tower caused progressive collapse. Progressive collapse is defined by the American Society of Civil Engineering in the commentary C1.4 for ASCE

7-05 as "the spread of an initial local failure from element to element eventually resulting in the collapse, of an entire structure or a disproportionately large part of it. The abnormal loading arising due to loss of load bearing vertical element is not considered during analysis and design of structures using any general design codes. Recently few institutions came up

Sujaykumar R. Sanglikar, PG Student, SDMCET, Dharwad, India. E-mail:sujaykumar947@gmail.com

R. Prasanna Kumar, Managing Director, Smart Minds Engineering Pvt.Ltd, Bengaluru. E-mail:prasanna@smartmindsengg.com

M.S. Bhandiwad, Assistant Professor, SDMCET, Dharwad, India. E-mail:mallucv014@gmail.com

DOI:10.9756/BIJMMI.8174 with the specifying guidelines. General Service Administration (GSA) and Department of Defense (DoD) are mainly used and followed for the purpose of analysis and design against progressive collapse.

There are three main analysis procedures prescribed by GSA and DoD they are linear static, nonlinear static and dynamic analysis. An advanced structural analysis computer programme ETABS is used to perform the sophisticated progressive collapse analysis.

Li et al. [1] validated a fiber based model by quantifying the effects of numerical procedures with varied iterations. Many analysis procedures using FE codes and algorithms are studied and formulated by Brunesi \& nascrmbene [2] for progressive collapse analysis.

First of all, the progressive collapse sensitivity to the nonlinear analysis method and structural modeling technique was assessed in the case of structures in four zones prescribed by IS 1893-2002.the structures were designed incompliance with Indian standard building codes.

\section{OBJECTIVE}

During past few decades,progressive collapse has received enough attention but progressive collapse due to seismic actions haven't received much attention even after it's the main reason of progressive collapse. This study investigates the behavior of structures in seismic actions due to loss of vertical load bearing element i.e columns.

\section{A. GSA Guidelines}

GSA guidelines introduced two design approaches. [3] One is direct design approach and another is indirect design method. Alternate path method and Specified local resistance methods are direct deign methods. The SLR design approach deals with stability offered by structure by its connections to withstand any abnormal loading caused due to loss of any load bearing element.it can be applied prior to design and as well to improve an existing structure. The APM aspires to limit the extent of damage due to failure caused by loss of a local element that leads to abnormal loading that is redistributed by adjacent members of the structure. Indirect method, Tie force method is adopted. It assumes the abnormal loading can be resisted by enhancing the continuity, structural redundancy and ductility the calculations require a sophisticated stimulation and the output data acquired is of large size in GBs. Indirect method can't be applied to dynamic analysis as in case of earthquake analysis. Thus, APM method is preferred 
over all the other methods for its simplicity and adoptability for both static and dynamic analysis procedure for reinforced concrete structures subjected to seismic actions. Based on the GSA guidelines [4], [5], [6], [7]

To determine the potential of progressive collapse for a structure, following four different column removal cases are considered to determine the response of the structure and to know key effects of different parameters on deformation arising due to column loss:

1) A column located at the corner of the building in first floor

2) An exterior column near middle of long side of the building in first floor

3) A column interior to perimeter, intersecting column lines

\section{B. Nonlinear Static Analysis}

It deals with geometric and material irregularities of the structures. Push down analysis was performed to determine response of structure using function of loading accordance to GSA guidelines, A load combination of 2(DL+0.25LL) (DL is Dead Load, LL is Live load) was considered for the analysis.

Following procedure was followed:

1) Static analysis with permanent loads is performed so as to determine internal forces of the removal member.

2) A load bearing member will be removed and internal force at that removal joint is added along with permanent load.
3) The internal force of the removed member is applied in the vertical direction at the end of removal element.

4) The push down force is increased incrementally so as to get target displacement or to the point at which collapse point of the structure.

5) Now check the Demand capacity ratio in the adjacent structural members where column has been deleted.

6) The DCR can be derived from the following formulation

$$
D C R=\frac{Q u d}{Q c e}(1)
$$

Where,

Qud= Resulting actions (Internal forces \& moments)

Qce $=$ Expected strength of the Component or element

If the DCR value of the beams adjacent to the removed column exceeds 2 then that member is more vulnerable to progressive collapse.

Table 1: Material Properties

\begin{tabular}{|l|c|}
\hline Materials & Grade \\
\hline Concrete & $\mathrm{M} 40$ \\
\hline Reinforcing steel & $\mathrm{Fe} 550$ \\
\hline
\end{tabular}

Table 2: Loads

\begin{tabular}{|l|l|l|}
\hline Live load & 4 & $\mathrm{KN} / \mathrm{m}^{2}$ \\
\hline Superimposed dead load & 1.5 & $\mathrm{KN} / \mathrm{m}^{2}$ \\
\hline Wall load & 14.7 & $\mathrm{KN} / \mathrm{m}$ \\
\hline Wind speed & 50 & $\mathrm{~m} / \mathrm{s}$ \\
\hline
\end{tabular}

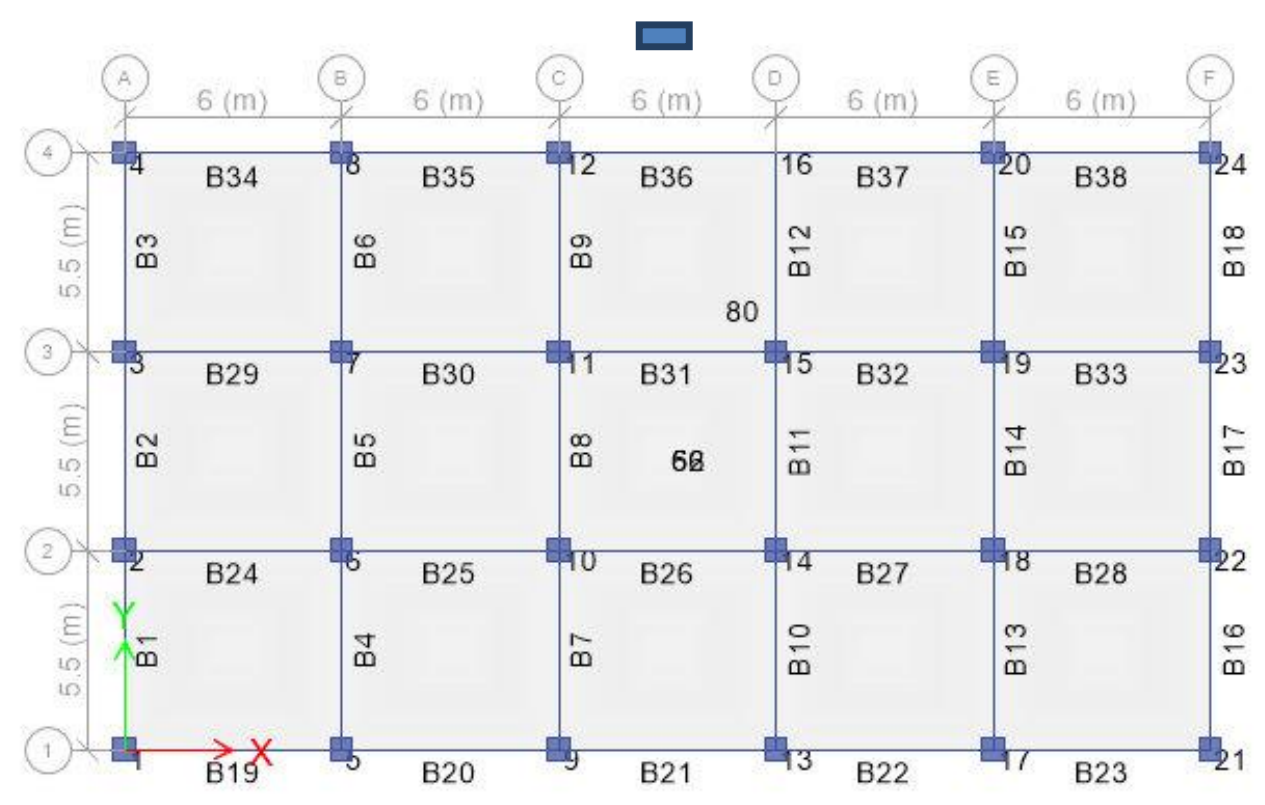

Figure 1: Plan View 


\section{Performance Assessment}

A Column Located at the Corner of the Building in First Floor Removed

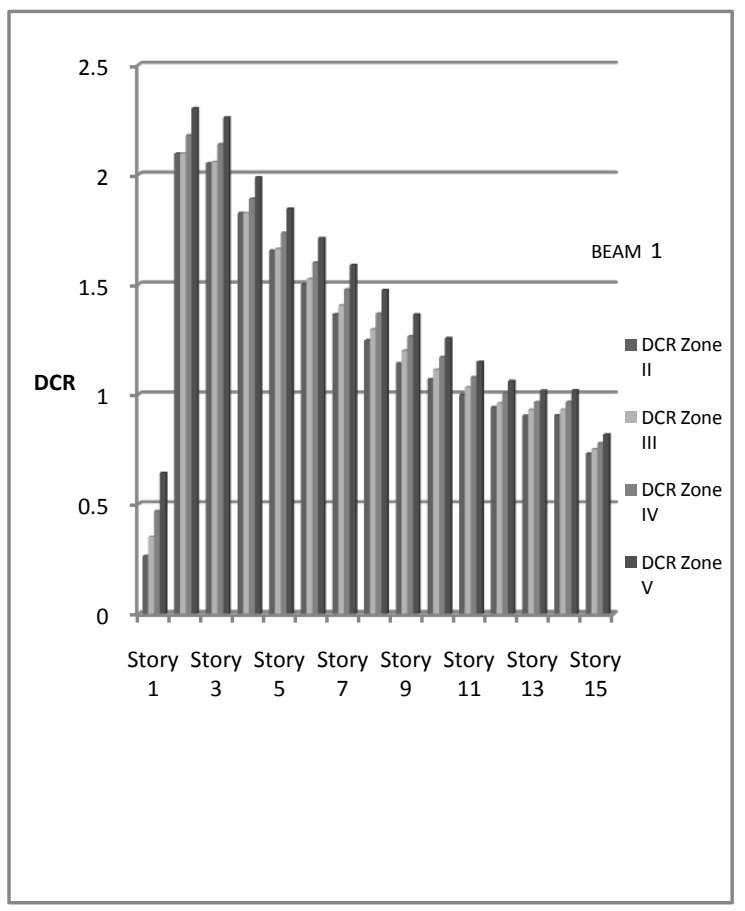

Figure 2: Comparison of DCR Values of BEAM 1 Due to Removal of Column A1 in Different Zones

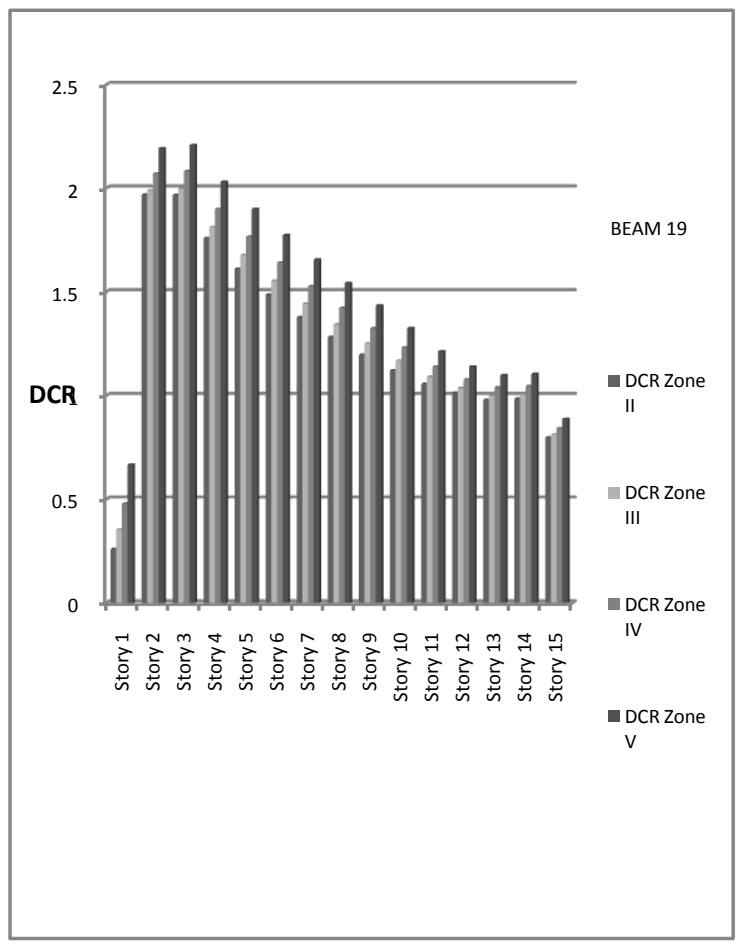

Figure 3: Comparison of DCR Values of BEAM 19Due to Removal of Column A1 in Different Zones
An Exterior column Near Middle of Long Side of the Building in First Floor

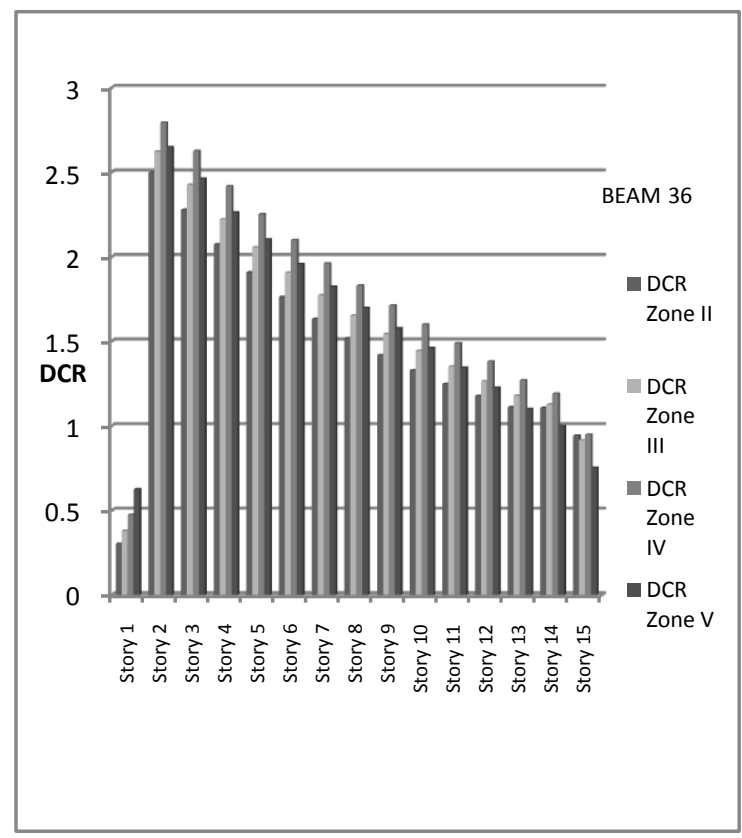

Figure 4: Comparison of DCR Values of BEAM 36Due to Removal of Column D4 in Different Zones

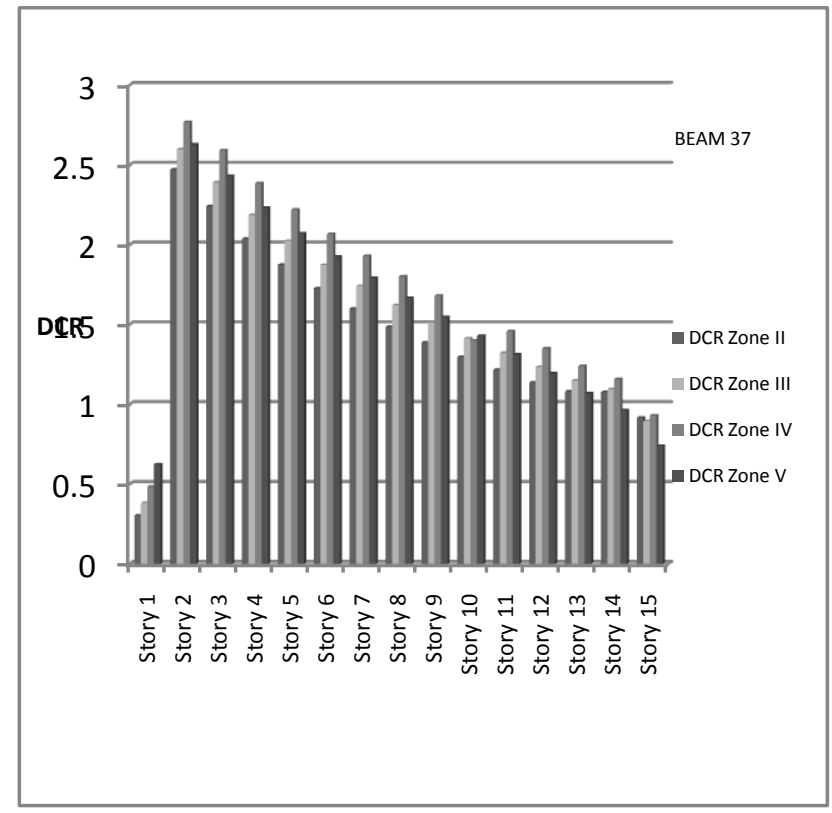

Figure 5: Comparison of DCR Values of BEAM 37Due to Removal of Column D4 in Different Zones 


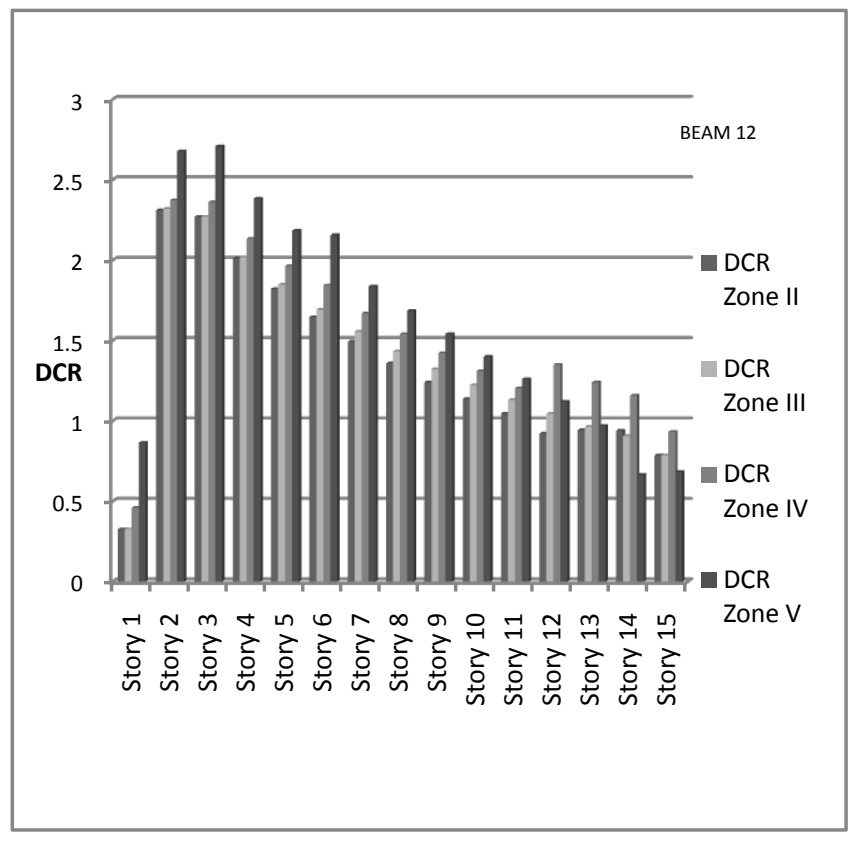

Figure 6: Comparison of DCR Values of BEAM 12Due to Removal of Column D4in Different Zones

A Column Interior to Perimeter, Intersecting Column Lines

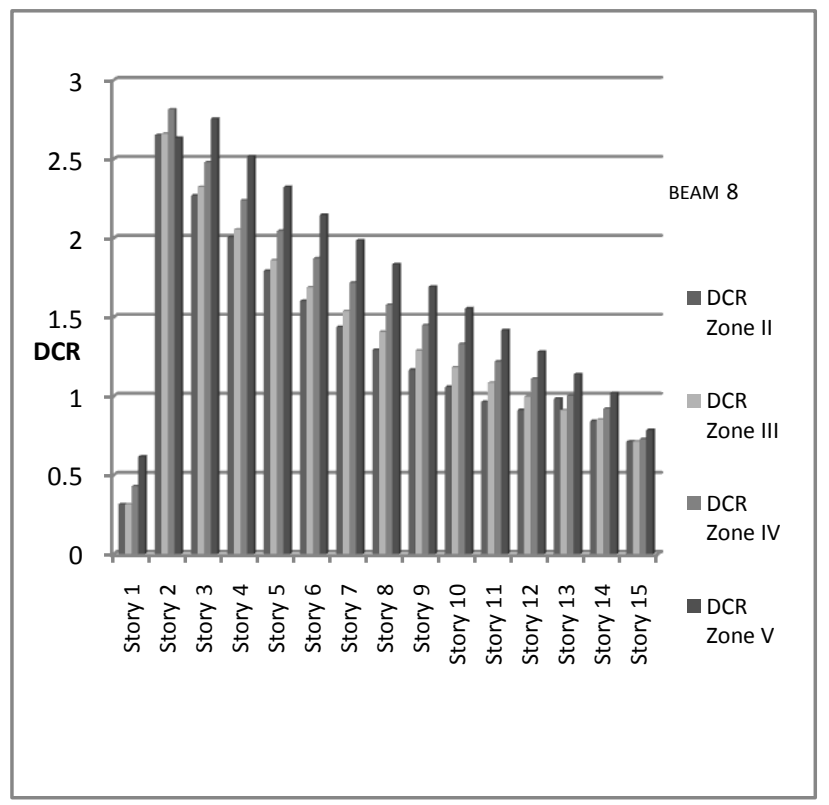

Figure 7: Comparison of DCR Values of BEAM 8Due to Removal of Column C11in Different Zones

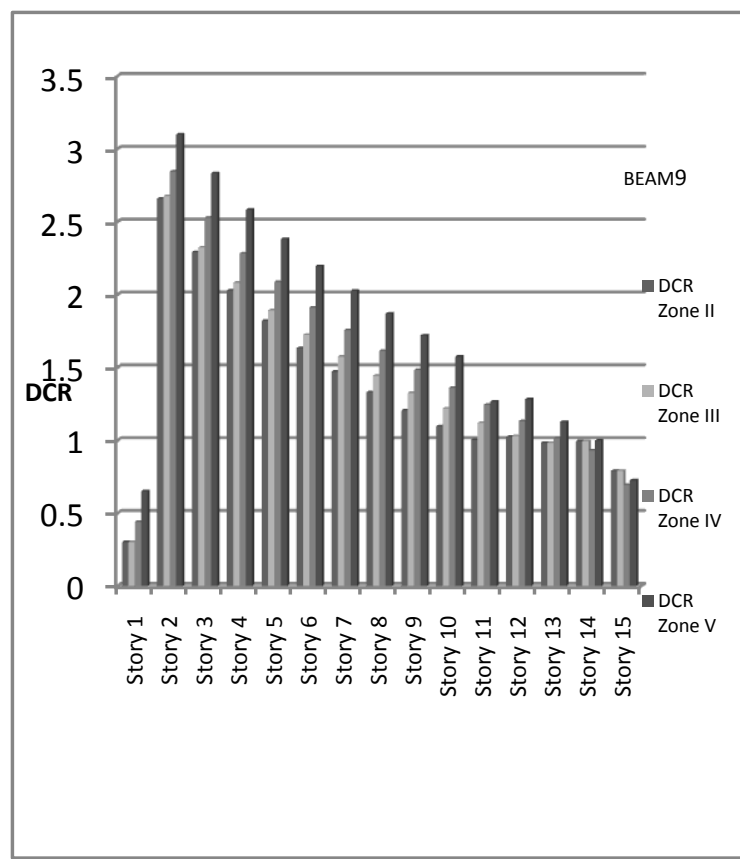

Figure 8: Comparison of DCR Values of BEAM 9 Due to Removal of Column C11in Different Zones

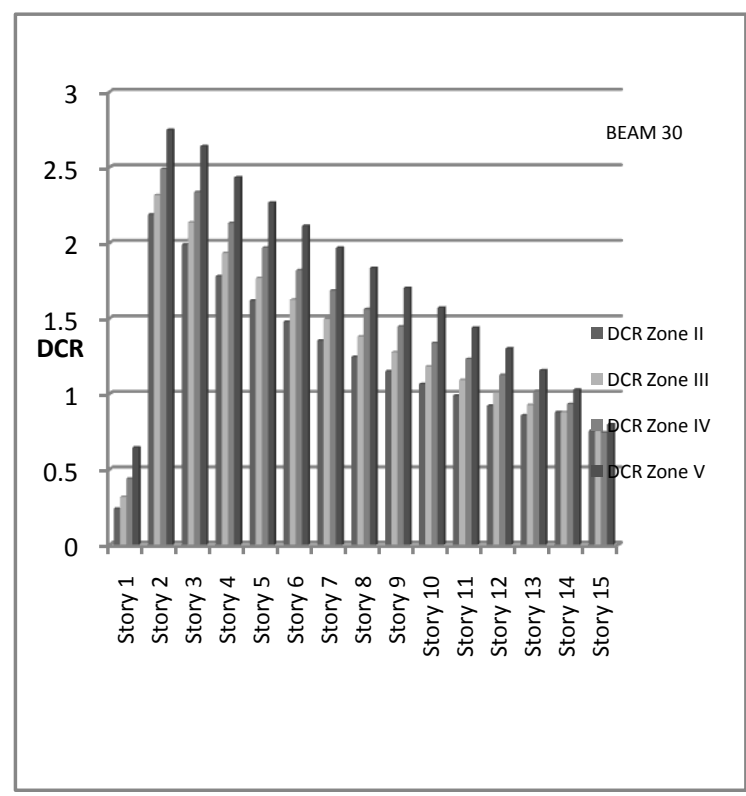

Figure 9: Comparison of DCR Values of BEAM 30 Due to Removal of Column C11in Different Zones 


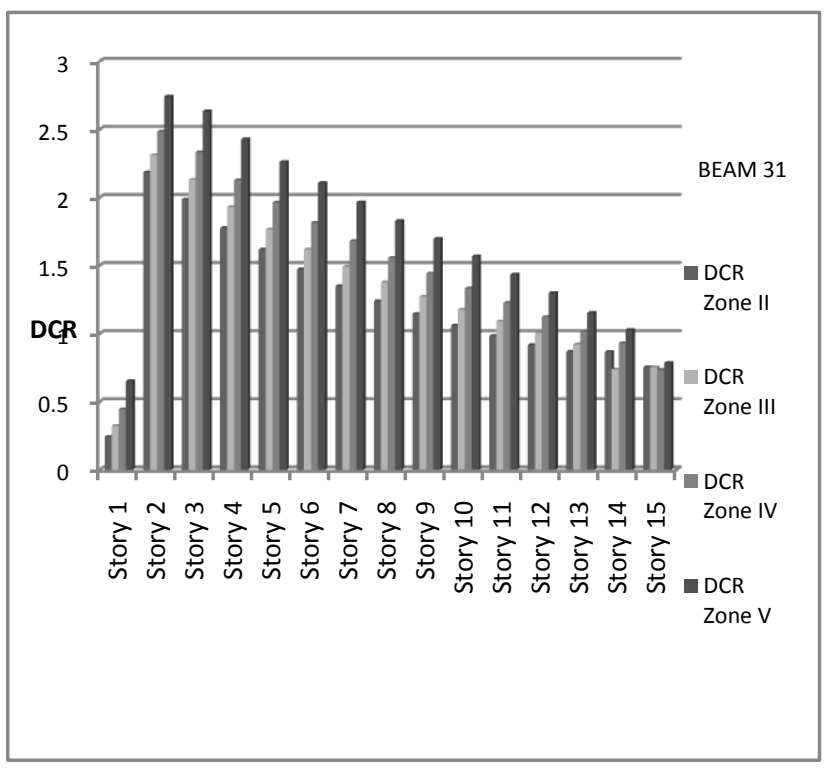

Figure 10: Comparison of DCR Values of BEAM 30 Due to Removal of Column C11 in Different Zones

\section{Progressive Collapse Analysis Results}

\section{1) Assessment of Load Bearing Beams, Due to Column} Removal Position in Plan

Based on the regulations presented in section $\mathrm{A}$, the most critical conditions in removing load bearing columns ware considered and adjacent beams ware evaluated for the load distribution through alternate path method.

Nonlinear static analysis using push down method was performed to monitor the demand capacity ratios of the adjacent beams of the column removed.

\section{a) Column Located at the Corner of the Building in First Floor Removed}

Figure 2 shows the DCR values of beam 1due to removal of column C1.the values of DCR for all zones exceeds 2 for story 2 and 3 indicating the failure of member leading progressive collapse.in story 4, 5 and 6 DCR values are close to 2 indicating its vulnerability to progressive collapse.

Figure 3 shows the DCR values of beam 19, it's observed that the DCR values exceed 2 for story 2, 3 and 4 indicating poor robustness of the beams due to loss of column.

It's further observed that the beam 1 and beam 19 had DCR values less than 2 in zones II and III due to its ductile design which offers better stability compared to ductile design of Zone IV and V.

\section{b) An Exterior Column Near Middle of Long Side of the Building in First Floor}

Figure 4, figure 5 and figure 6 indicates DCR values of beam 36 , beam 37 and beam 12 where DCR values exceed 2 for story $2^{\text {nd }}, 3^{\text {rd }}$ and $4^{\text {th }}$ indicating failure of beams. Whereas DCR values of zone II ware with in limit offering resistance to collapse.
Comparing DCR of all beams in different zones beam 36 and 37 suffer major damage as the span of the beam increases leading sagging of beams.

Figures must be numbered using Arabic numerals.

\section{c) A Column Interior to Perimeter, Intersecting Column Lines}

Figure 8 shows the DCR values beams 8 , the limiting value exceeds in stories $2^{\text {nd }}, 3 \mathrm{rd}$ and $4^{\text {th }}$ in all zones indicating failure of beam 8.The DCR values in Zone IV and V exceeds 2 in stories $2^{\text {nd }}$ to $6^{\text {th }}$ indicating failure of beams.

Figure 9 shows DCR values of Beam 9, in Zone $\mathrm{V}$ the value exceeds 2 for stories $2^{\text {nd }}$ to $7^{\text {th }}$ indicating total damage of beam and leading to progressive collapse.in all other zones the DCR values exceed limiting value in story $2^{\text {nd }}$ to $4^{\text {th }}$.

Figure 10 and 11 shows DCR values of beams 30 and 31 ,its observed that in zone $\mathrm{V}$ the value exceeds 2 in story $2^{\text {nd }}$ to $6^{\text {th }}$.in zone II the values is within 2 indicating resistance against Progressive collapse.

\section{CONCLUSION}

1. The pushdown analysis provides insight of elastic and inelastic behavior of the structural members subjected to earthquake forces that might lead to progressive collapse. The moments drastically increased up to $30 \%$ after removal of the columns.

2. The results specify that the resistance offered by adjacent beams of the column removed are insufficient to prevent progressive collapse

3. The moments after removal analysis ware about 10$15 \%$ greater for SMR frames compared to OMR frames.The ordinary moment resisting frames (OMRF) used in Zone II performed better than that of Special Moment resisting frames (SMRF) of Zone III,IV and $\mathrm{V}$. The OMRF resisted the sudden downward force better than that of SMRF.

4. The ductile SMR frames lacking longitudinal reinforcement failed to redistribute loads like OMR frames resisting progressive collapse.

5. The columns removed at the corner and column removed interior to intersecting column lines suffered major damage compared to column removed in the middle of the corner, The DCR values at the corner are $10-20 \%$ greater than the DCR values of other column removal cases.

\section{REFERENCES}

[1] Y. Li, X.Z. Lu, H. Guan, L.P. Ye, "An improved tie force method for progressive collapse resistance design of reinforced concrete frame structures", Vol. 33, No. 10, Pp. 2931-2942, 2011.

[2] E. Brunesi and R. Nascimbene, "Extreme response of reinforced concrete buildings through fiber force-based finite element analysis", Eng. Struct, Vol. 69, Pp. 206-215, 2014.

[3] Z. Li and Y. Shi, "Methods for progressive collapse analysis of building structures under blast and impact loads", Transactions of Tianjin University, Vol. 14, Pp. 329-339, 2008.

[4] A. Elshaer, H. Mostafa and H. Salem, "Progressive collapse assessment of multistory reinforced concrete structures subjected to seismic actions", KSCE Journal of Civil Engineering, Pp. 1-11, 2016. 
[5] A. Mark, Asamoah, Nobel obeng Ankamah Effect of design ductility on the progressive collapse potential of RC framed structure designed to euro code 8 .

[6] E. Livingston, M. Sasani, M. Bazan and S. Sagiroglu, "Progressive collapse resistance of RC beams", Engineering Structures, Vol. 95, Pp. 61-70, 2015.

[7] R. Alireza, S. Alireza hahin and H. Farzad, "Progressive collapse resisting capacity of reinforced concrete load bearing wall structures", J. Cent. South Univ., Vol. 22, Pp. 2730-2738, 2015.

[8] H.S. Kim, J. Kim and D.W. An, "Development of integrated system for progressive collapse analysis of building structures considering dynamic effects", Advances in Engineering Software, Vol. 40, No. 1, Pp. 1-8, 2009.

[9] E. Brunesi, R. Nascimbene, F. Parisi and N. Augenti, "Progressive collapse fragility of reinforced concrete framed structures through incremental dynamic analysis", Engineering Structures, Vol. 104, Pp. $65-79,2015$

[10] F. Petrone, L. Shan and S.K. Kunnath, "Modeling of RC Frame Buildings for Progressive Collapse Analysis. International Journal of Concrete Structures and Materials, Vol. 10, No. 1, Pp. 1-13, 2016.

[11] A. Bassam, D.A. Izzuddin and Nethercot, "Assessment of Progressive Collapse in MultiStorey Buildings", Structures and Buildings, ARTICLE in STRUCTURES \& BUILDINGS JANUARY, Vol. 160, No. 4, Pp. 197-206, 2007. 